\title{
Effect of scanning speed on microstructure and properties of 12CrNi2Re alloy steel prepared by laser additive manufacturing
}

\author{
Suiyuan Chen ${ }^{a}{ }^{*}$, Ruixue Wang ${ }^{b}$, Jing Ma ${ }^{c}$, Jing Liang ${ }^{d}$, Tong Cui ${ }^{e}$,Changsheng Liu ${ }^{f}$ \\ Key Laboratory for Anisotropy and Texture of Materials(Ministry of Education), School of \\ Material Science and Engineering, Northeastern University, Shenyang 110819, China \\ achensy@smm.neu.edu.cn, b1730515703@qq.com, c738277405@qq.com, diangj@atm.neu.edu.cn, \\ ecuit@smm.neu.edu.cn, ${ }^{\mathrm{f}}$ csliu@mail.neu.edu.cn
}

Keywords: laser additivemanufacturing technology; Bainite transformation; 12CrNi2Re alloy steel; nuclear power emergency diesel generator crankshaft.

\begin{abstract}
CrNi2Re alloy steel powder was used as raw material, 12CrNi2Re alloy steel with rectangular(10mm thick) was prepared by laser additive manufacturing. Effect of scanning speed on microstructure and properties of 12CrNi2Re alloy steel were studied by OM, SEM, XRD, micro hardness tester and tensile test.The results show that the phases composition of 12CrNi2Re alloy steel are bainite and carbide $(\mathrm{Cr}, \mathrm{Fe})_{7} \mathrm{C}_{3}$. Thermal accumulation was led due to thermal cycling during the preparation of samples by laser additive manufacturing, the heat loss was much lower than the laser input energy, the cooling rate was slow and bainite transformation happened during the preparation of $12 \mathrm{CrNi} 2 \mathrm{Re}$ samples. The scanning speeds increased from $3 \mathrm{~mm} / \mathrm{s}$ to $7 \mathrm{~mm} / \mathrm{s}$, the laser energy input decreased accordingly, the thermal accumulation temperature decreased when 12CrNi2Re alloy steel samples prepared by laser additive manufacturing, the isothermal transformation time of granular bainite was shorter, the size of the granular bainite became smaller as the scanning speed increased. When the scanning speed was $5 \mathrm{~mm} / \mathrm{s}$, the hardness, tensile strength, yield strength, elongation and contraction rate of sample are favorable, and it has good application value.
\end{abstract}

\section{Introduction}

As the important components of nuclear power emergency diesel generator, the performance and service life of the crankshaft play an important role in the safety of nuclear power[1-3]. At present, the nuclear power emergency diesel generator crankshaft is prepared by forging, heat treatment (quenching) and surface spraying. The crankshaft prepared by this production process has high strength and toughness, but the structure of crankshaft is complicated, and it is impossible to realize the scientific matching between the high wear resistance on surface and the high strength and toughness of the core. Moreover, this manufacturing process is complex and the production cycle is too long, it can not meet the demand of nuclear power development [4-7].

Laser additive manufacturing technology is different from the traditional components preparation process, it have the advantages of near-net shape and rapid prototyping, and the parts produced by this technology have high performance, favorable combination property and good density, it greatly shorten the production cycle of components. It also has the advantage of not requiring large production equipment and moulds. Therefore, it has vital research value to prepare the nuclear power emergency diesel generator crankshaft by laser additive manufacturing technology[7-9].

In this paper, 12CrNi2Re alloy steel powder was used as raw material, 12CrNi2Re alloy steel with rectangular(10mm thick) was prepared on the surface of Q235 steel by FL-Dlight02-3000W semiconductor laser, the micro-structure, longitudinal hardness and mechanical properties of 
12CrNi2Re alloy steel samples were studied, the effect of scanning speed on microstructure and properties of 12CrNi2Re alloy steel was investigated.

\section{Experimental Materials and Methods}

\subsection{Sample preparation}

The raw material was12CrNi2Re alloy steel powder prepared by VIGA (vacuum induction smelting gas atomization). The chemical composition of 12CrNi2Re powder were composed of 0.13wt.\% C, 0.85wt.\% Cr, 0.36wt.\% Si, 0.51wt.\% Mn, 2.13wt.\% Ni, 0.63wt.\% Re, 95.39wt.\% Fe. The mean particle diameter of 12CrNi2Re alloy powder was 66.27um, powder flowability was $16.79 \mathrm{~s} / 50 \mathrm{~g}$, hollow spheres was less than $2 \%$ and the sphericity was greater than $29.9 \%$. 12CrNi2Re alloy steel sample was prepared on the surface of Q235 steel under parameter condition such as the laser power of $1900 \mathrm{~W}$, the powder feeding rate of $4.5 \mathrm{~g} / \mathrm{min}$ and the lap ratio of $40 \%$ by FL-Dlight02-3000W semiconductor laser with coaxial powder-feed, the samples size was $50 \times 30 \times 10 \mathrm{~mm}$, the spot of laser was $4.0 \mathrm{~mm} \times 4.0 \mathrm{~mm}$, the scanning direction of layers was parallel each others.

\subsection{Experimental detection methods}

The micro-structure was investigated with OLMPUS-GX71 optical microscope, the samples for the OM observations were etched with $4 \%$ nitial. Hardness was collected in WILSON-WOLPER-450SVD(100g), hardness values were taken on the longitudinal section of samples. The phase composition of the samples was characterized by X-ray diffraction(XRD, pw3040/60) using $\mathrm{Cu}-\mathrm{K}_{\alpha}$ radiation angle between $20^{\circ} \sim 120^{\circ}\left(\mathrm{Vs}=4^{\circ} / \mathrm{min}, \mathrm{U}=40 \mathrm{KV}, \mathrm{I}=200 \mathrm{~mA}\right)$. The characterization of the micro-structure of the samples were carried out using a scanning electron microscope(JSM-6510A) with an EDS analyzer and a transmission electron microscope(TECNAIG220). Tensile properties were collected in AG-X100KN universal material testing machine and tensile rate was $0.2 \mathrm{~mm} / \mathrm{s}$.

\section{Results and discussion}

Fig. 1 is the morphology of molten pool at different scanning speeds. Because the scanning speed was smaller, the time of laser acting on the same region was longer, the burning loss of alloy elements was serious and the molten pool was deep, the gas generated from the burning of alloy elements failed to escape in time, so there is hole defect in Fig. 1(a) and Fig. 1(b). Because the scanning speed was appropriate, $12 \mathrm{CrNi2Re}$ alloy powders were melted and the burning loss of alloy elements was less, the molten pool has good morphology and there are dense structure and no porosity as shown in Fig. 1(c). The scanning speed was greatly increased, the action time between laser and 12CrNi2Re alloy powder was shortened, the penetration of molten pool became shallow, metallurgical bonding between layers was poor.

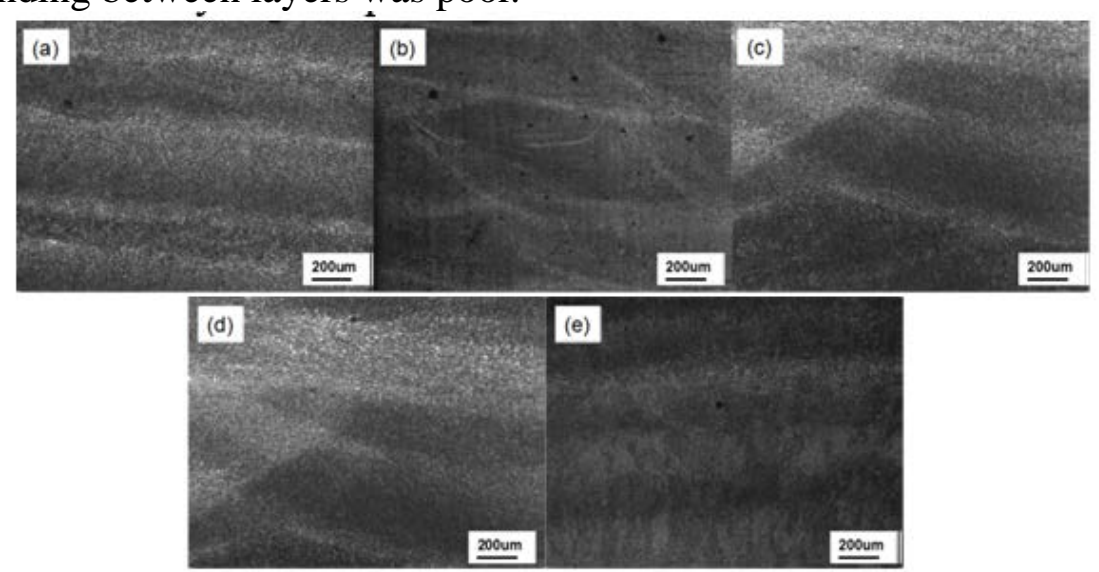

Fig.1 The morphology of molten pool at different scanning speeds (a)-3mm/s; (b)-4mm/s; (c)-5mm/s; (d)-6mm/s; (e)-7mm/s 
Fig. 2 is the microstructure of samples at different scanning speeds. Thermal accumulation was led due to thermal cycling during the preparation of samples by laser additive manufacturing, the heat loss was much lower than the laser input energy, the cooling rate was slow and bainite transformation happened during the preparation of 12CrNi2Re sample. So the microstructure of 12CrNi2Re alloy steel prepared by laser additive manufacturing at different scanning speeds was granular bainite. The scanning speeds increased from $3 \mathrm{~mm} / \mathrm{s}$ to $7 \mathrm{~mm} / \mathrm{s}$, the laser energy input decreased accordingly, the thermal accumulation temperature decreased when 12CrNi2Re alloy steel samples prepared by laser additive manufacturing, the isothermal transformation time of granular bainite was shorter, the size of the granular bainite became smaller as the scanning speed increased. The size of granular bainite has a great influence on the strength and toughness of samples.

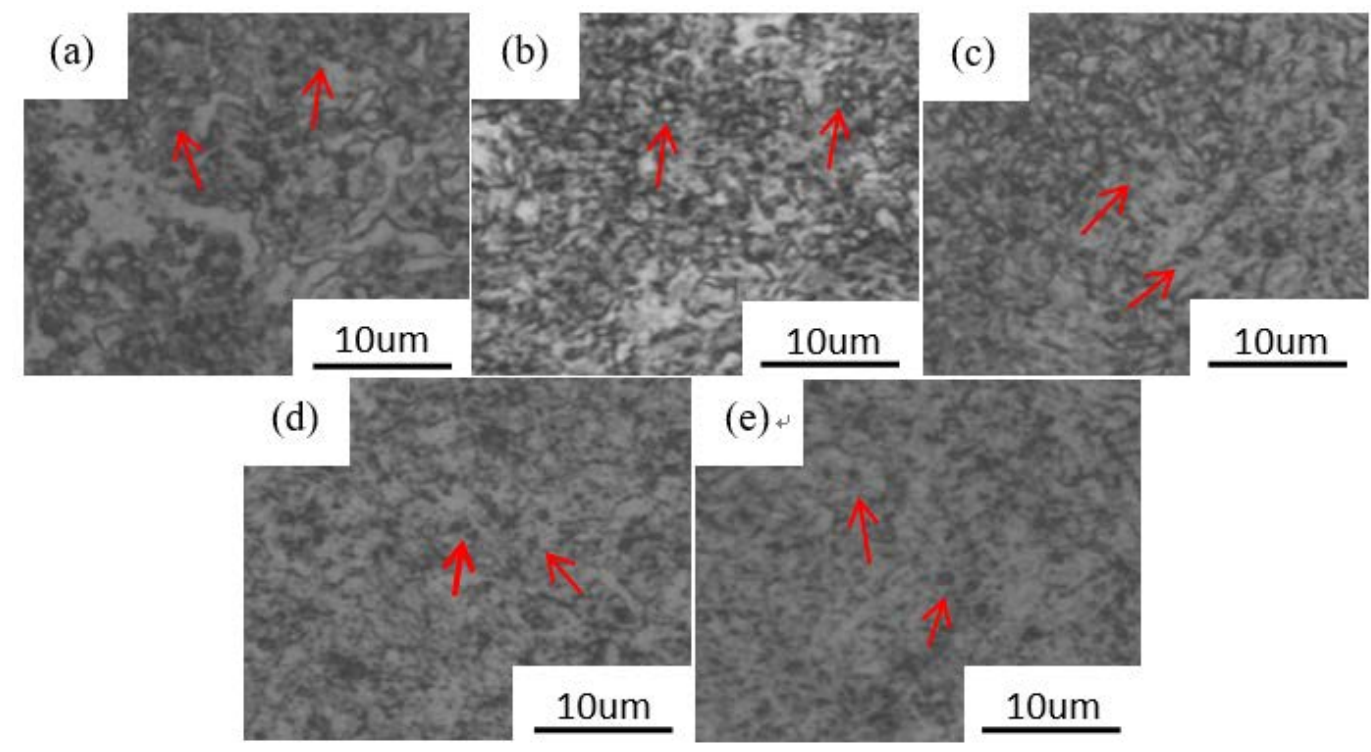

Fig.2 Microstructure of samples at different scanning speeds

(a)-3mm/s; (b)-4mm/s; (c)-5mm/s; (d) $6 \mathrm{~mm} / \mathrm{s}$; (e)-7mm/s

Fig. 3 is the longitudinal section hardness distribution curve of samples at different scanning speeds. The hardness of samples generally increased at first and then decreased with the increased of scanning speed. The size and distribution of granular bainite has influence on the hardness of the samples, the size difference of the granular bainite in the samples is not more than $1 \mathrm{um}$, so hardness difference of samples is small. The average hardness of sample at the scanning speed of $5 \mathrm{~mm} / \mathrm{s}$ is highest and it's about 334.7HV.

Fig. 4 is the XRD of samples at different scanning speeds. The phases composition of 12CrNi2Re alloy steel samples were bainite and carbide $(\mathrm{Cr}, \mathrm{Fe}){ }_{7} \mathrm{C}_{3}$.

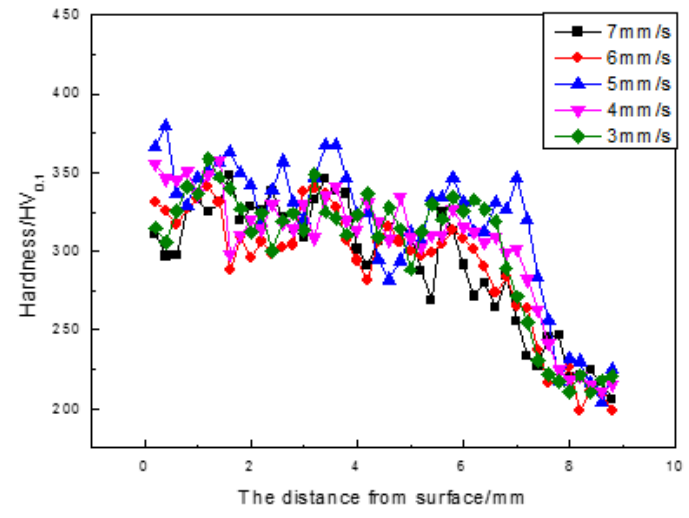

Fig. 3 The longitudinal section hardness distribution curve of samples

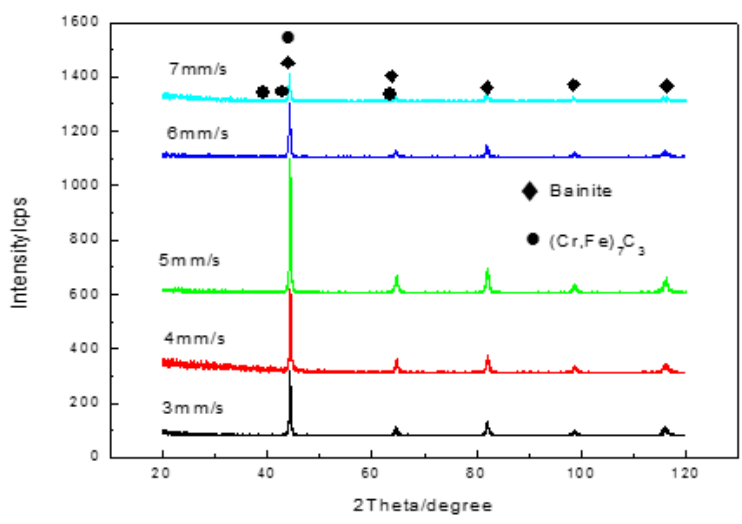

Fig. 4 The XRD of samples at different scanning speeds

Fig. 5 showed the tensile curve of $12 \mathrm{CrNi2Re}$ alloy steel samples at room temperature, Table 1 is the data of tensile properties at room temperature. With the increase of scanning speed, the 
tensile strength, yield strength, elongation and contraction rate increased at first and then decreased. This trend was mainly related to the size and distribution of granular bainite, the size of granular bainite decreased and the grain boundary area increased, the dislocation density increased. Therefore, the scanning speeds increased from $3 \mathrm{~mm} / \mathrm{s}$ to $5 \mathrm{~mm} / \mathrm{s}$, tensile strength, yield strength, elongation and contraction rate were improved combined with Fig.2. While the scanning speed increases from $5 \mathrm{~mm} / \mathrm{s}$ to $7 \mathrm{~mm} / \mathrm{s}$, the size of granular bainite was even smaller, because the poor bonding between deposition layers result from low scanning speeds. The tensile strength, yield strength, elongation and contraction rate showed decline trend. Fig. 6 is the tensile fracture of sample at $5 \mathrm{~mm} / \mathrm{s}$, the dimples and the second phase particles are evidently seen, so the fracture mode is toughness fracture. The spherical particles is carbide is the carbide $(\mathrm{Cr}, \mathrm{Fe})_{7} \mathrm{C}_{3}$.

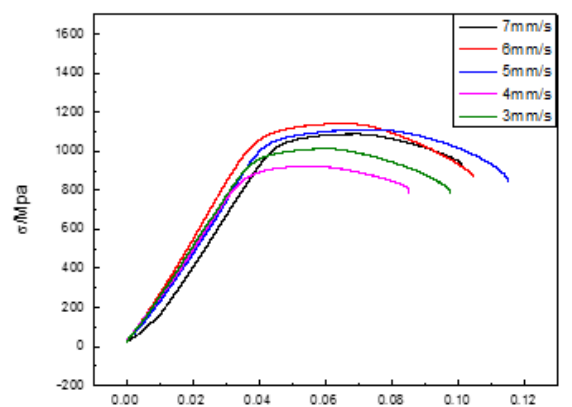

Fig.5 The tensile curve of $12 \mathrm{CrNi} 2 \mathrm{Re}$ alloy steel samples

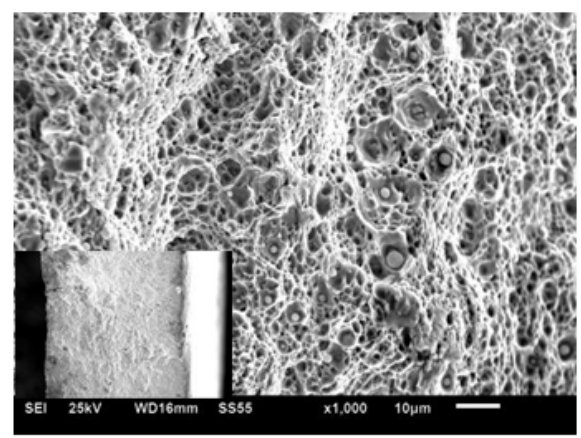

Fig.6 Tensile fracture of sample at $5 \mathrm{~mm} / \mathrm{s}$

Table 1The tensile data of 12CrNi2Re alloy steel samples

\begin{tabular}{ccccc}
\hline $\mathrm{Vs} /(\mathrm{mm} / \mathrm{s})$ & $\sigma_{\mathrm{s}} / \mathrm{Mpa}$ & $\sigma_{0.2} / \mathrm{Mpa}$ & $\delta / \%$ & $\psi / \%$ \\
\hline 3 & 1011.51 & 951.47 & 9.78 & 21.40 \\
4 & 924.75 & 874.83 & 8.54 & 24.11 \\
5 & 1111.28 & 1045.46 & 11.54 & 30.30 \\
6 & 1141.56 & 1060.82 & 10.48 & 27.34 \\
7 & 1087.71 & 1038.47 & 10.14 & 26.67 \\
\hline
\end{tabular}

\section{Conclusions}

The phases composition of 12CrNi2Re alloy steel prepared by laser additive manufacturing at different scanning speeds were bainite and carbide $(\mathrm{Cr}, \mathrm{Fe})_{7} \mathrm{C}_{3}$. Thermal accumulation was led due to thermal cycling during the preparation of samples, the heat loss was much lower than the laser input energy, the cooling rate was slow and bainite transformation happened. The scanning speeds increased from $3 \mathrm{~mm} / \mathrm{s}$ to $7 \mathrm{~mm} / \mathrm{s}$, the laser energy input decreased accordingly, the thermal accumulation temperature decreased when 12CrNi2Re alloy steel samples prepared by laser additive manufacturing, the isothermal transformation time of granular bainite was shorter, the size of the granular bainite became smaller as the scanning speed increased.

\section{Acknowledgments}

This work was financially supported by National Key R\&D Program of China(2016YFB1100201), National Natural Science Foundation of Liaoning United fund (U1508213). 


\section{References}

[1] J. A. Zhou, Energy and energy conservation, 16(2015)78-79.

[2] J. S Hur, M. S. Roh, AIP Conference Proceedings, 1584(2014)15-21.

[3] K. Raja, N. Theivarajan, International Conference on Electrical Energy Systems, 32(2011)302 - 307.

[4] B.H.Wei, Nuclear power R\&D, 7(2014)104-108.

[5] Y Kimura, T Inoue, Metallurgical and Materials Transactions A, 44(2013)560-576.

[6] L.Cheng, PTCA(Part: A PHYS. TEST. ) 41(2005)314-317.

[7] E. Kautzmann, Laser material processing, 28(2013)42-50.

[8] H.Y.Li, S.L.Gong, F.Sun, Aeronautical Manufacturing Technology, 20(2012)26-31.

[9] R.S.Amano, P.K.Rohatgi, Material Science \& Engineering A, 528(2011)6680-6693. 